\title{
A Giant Paraovarian Cyst in a single woman in her third decade:
}

\section{A case report}

Hisham Hussein Imam

Department of Obstetrics \& Gynecology, Minia University, Minia, Egypt

\section{INTRODUCTION}

Paraovarian cysts (PCs) are cystic tumors that can be encountered between the ovarian hilum and the ovarian fimbria located within the mesosalpinx and broad ligament, being usually diagnosed within the $3 \mathrm{rd}$ and 4 th decade of life $[1]$.

These lesions are usually benign, accounting for $5 \%$ to $20 \%$ of all adnexal tumors, and they may originate from the Müllerian (paramesonephric) or Wollfian (mesonephric) ducts, or mesothelium [2]. Sixty eight per cent of the PCs originate from the mesothelium that covers the peritoneum, being lined with flattened epithelium. Nevertheless, 30\% of them originate from the paramesonephric remnants, being lined with secretory, ciliated columnar, or cuboidal epithelium, while the remaining $2 \%$ originate from the mesonephric remnants, and are characterized by cuboidal or flattened epithelium. $[3,4]$

Paraovarian cysts (PCs) are usually diagnosed during the 3 rd or 4 th decade of life, and up to $80 \%$ of them are asymptomatic being diagnosed incidentally during a random abdominal ultrasound. However, in certain cases these patients can present with abdominal pain, nausea, or vomiting due to cystic complications, such as perforation, bleeding, excessive growth, torsion, and malignant transformation.[5,6] The prevalence of neoplastic PCs is usually very low.[7]

Diagnosis of both ovarian and Paraovarian Cysts are usually done using Ultrasonography (US), Computerized Topography (CT) and/or Magnetic Resonant Imaging (MRI) [1]. Ultrasonography (US) may show a cystic mass within the pelvis, usually an anechoic unilocular mass, but it may not show accurately the origin of this lesions. Moreover, it was reported that most often PCs are misdiagnosed as ovarian cysts (OCs), or other types of cystic pelvic masses, such as lymphoceles or peritoneal inclusion cysts.[8]. Moreover, Ultrasonography (US) is both examiner and patient dependent being more difficult in obese patients [9]. On the contrary, computed tomography (CT) or Magnetic Resonant Imaging (MRI) proved to be more useful in differentiating these 2 entities by showing a clear delimitation between the normal affected-side ovary and the unilocular cystic lesion [10]. Despite all these facts, the preoperative differentiation between PCs and OCs remains very difficult to be established and most often the precise diagnosis is established during the surgery [1].

\section{Case Summary}

A twenty nine years old single patient. She has long standing abdominal discomfort, dyspepsia, urinary frequency and presented with pelvi-abdominal mass. She has regular menses with no marked dysmenorrhea or any intermenstrual bleeding. Her past medical and surgical history is irrelevant. She is not smoking and do not drink alcohol. Her abdominal examination revealed a giant pelvi-abdominal mass cystic in consistency, not tense or tender and reaching up to the xiphisternum.

\section{Examination}

Her general examination is unremarkable with normal pulse, temperature, blood pressure and respiratory rate. Examination of the other systems reveal unremarkable findings. The patient body weight is $70.3 \mathrm{KG}$.

\section{Investigations}

Blood group O positive, Hemoglobin $13.9 \mathrm{gm} / \mathrm{dl}$, serum creatinine $0.82 \mathrm{gm} / \mathrm{dl}$ and RBS $110 \mathrm{mg} / \mathrm{dl}$. CT of abdomen and pelvis revealed a large pelvi-abdominal cystic lesion seen extending from the pelvic region till the epigastric region upwards. It measures $36 \times 30 \times 27 \mathrm{~cm}$ in its widest dimensions (Fig. 1,2,3) . It shows clear fluid density. It shows mass effect upon the related abdominal organs and the bowel loops in the form of displacement of bowel loops and pancreas. The cyst is clearly separated from the other abdominal organs. No loco-reginal enlarged lymph nodes. Clear Lung bases. Normal size and homogenous parenchymal attenuation of the Liver. Normal CT appearance of the gallbladder, pancreas, adrenals, spleen, both kidneys, aorta and IVC. Normal uterus with no lesions or masses. No free ascites. Impression: Large pelviabdominal cystic mass lesion mostly of ovarian origin, for further assessment.

\section{Operative Remarks}

Under general anesthesia and after abdominal preparation, the abdomen was opened in layers by a midline incision starting below the umbilicus and extending up around the umbilicus reaching to just below the xiphisternum to be able 


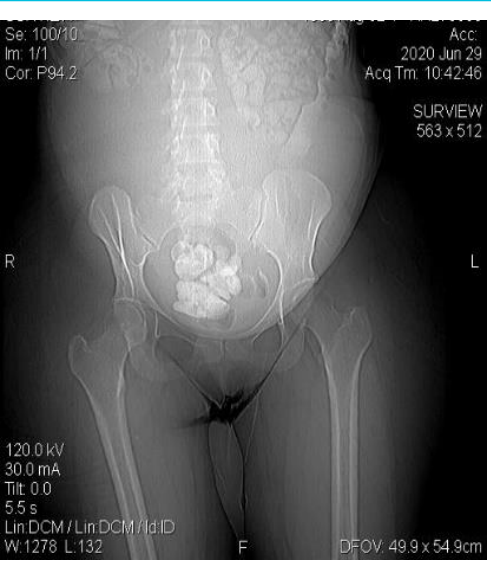

Fig. 1

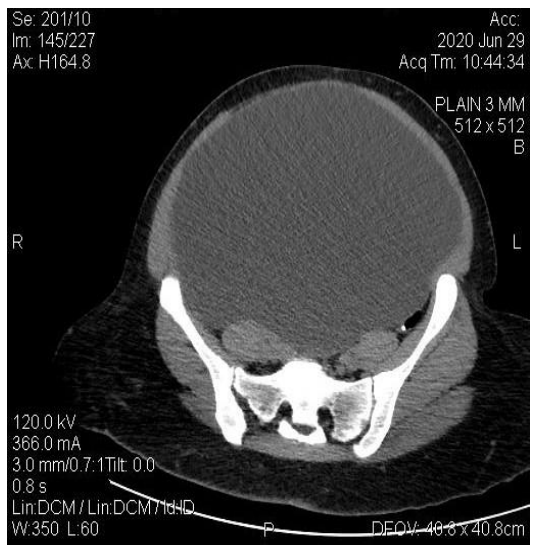

Fig. 2

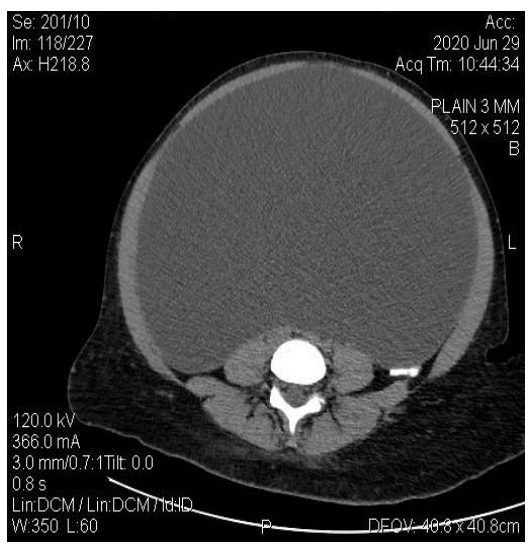

Fig. 3

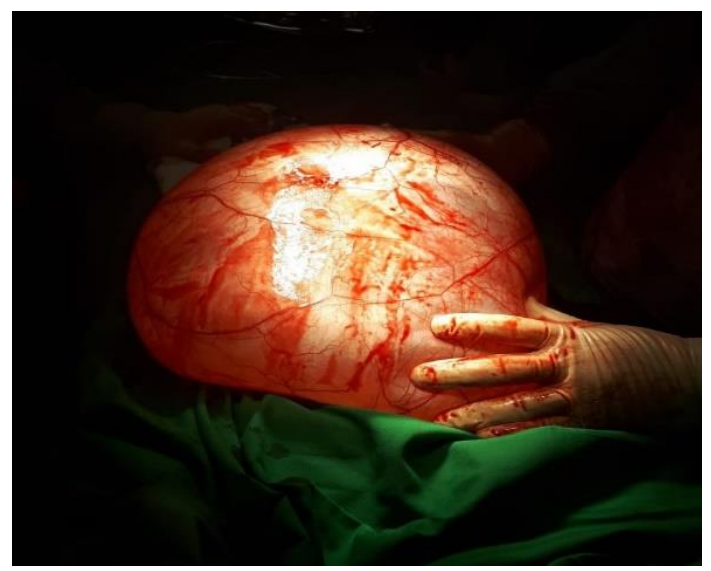

Fig. 4

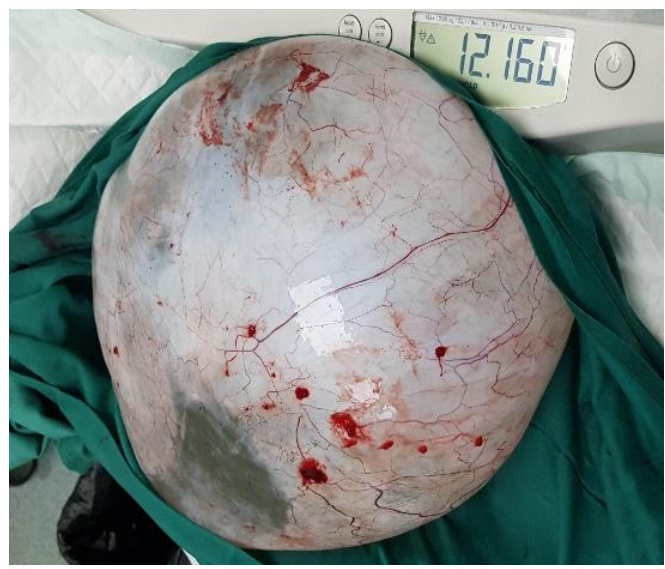

Fig. 5 to deliver the giant mass. There was no remarkable adhesions between the mas and surrounding structures. Examination of the mass revealed that it was arising from the right broad ligament with the right ovary looks normal in shape and size. The right fallopian tube was seen to be over stretched and present on the outer surface of the mass and looked unhealthy. The leaves of the broad ligament peeled off from the surface of the Paraovarian cyst. The Giant cyst removed from the abdomen. The redundant broad ligament tissues together with the overstretched right Fallopian tube was excised to avoid possible right tubal ectopic pregnancy in the future. The mass measures $35 \times 26 \times 18 \mathrm{~cm}$ and weighs $12160 \mathrm{gm}$ (Fig.4, 5). The abdomen was closed on layers and subcuticular sutures to the skin. The mass was sent to the laboratory for histopathological examination which revealed the presence of a huge benign Paraovarian and benign paratubal cysts. The postoperative period of the patient was uneventful and she was discharged home in the third postoperative day.

\section{Discussion}

Paraovarian cysts (PCs) constitute a homogeneous group of cystic masses originating from the mesosalpinx or the broad ligament, located in the proximity of the ovary and the Fallopian tube [11]. The histologic variants of PCs include mesonephric, mesothelial, and paramesonephric origins. [1, 2] The most frequent reported type was paramesonephric variant [12]. In our case, the giant PC was also located within the broad ligament and the histologic examination revealed no signs of neoplasia. The microscopic examination revealed the cyst to be lined by a single layer of columnar ciliated (tuballike) epithelium, thin layer of smooth muscle and underling congested fibrovascular tissue. Usually these PCs grow slowly, and they are discovered incidentally during the third or fourth decade of life, being rare during childhood or adolescence [6]. The preoperative differentiation between OCs and PCs is very difficult to be certainly established despite proper imagistic assessments. The clinical presentation of OCs and PCs are almost the same and the importance of differentiation is only theoretical because the management is also almost the same. This current case was diagnosed by CT as being ovarian in 
origin but without defining from which ovary it arises. Any trial to aspirate the cyst to decrease its size to minimize the size of the abdominal incision is not advisable to avoid spillage of the cysts contents which cannot be defined preoperatively [1]. Kazem Moslemi M and Yazdani Z, 2010 reported a Huge Ovarian Cyst in a Middle-Aged Iranian Female with an almost similar weight ( $12 \mathrm{KG}$ ) to our current patient, however, the mass was ovarian and in an older woman [13]. Kassidi F, et al. 2017, reported a successful Management of a Giant Ovarian Cyst in a 32-year old Moroccan woman [14]. Albers C E, Ranjit E, Sapra A, et al, 2020, reported bilateral multicystic ovarian masses in a 58 years old woman and advised that (Clinician Beware, Giant Ovarian Cysts are Elusive and Rare) [15].

\section{References}

1. Mărginean CO, Mărginean C, Meliţ LE, Săsăran VŞ, Poruţiu M, Mărginean CD. An incidental diagnosis of a giant paraovarian cyst in a female teenager: A case report. Medicine (Baltimore). 2018;97(48):e13406. doi:10.1097/MD.0000000000013406

2. Savelli L, Ghi T, De Iaco P, et al. Paraovarian/paratubal cysts: comparison of transvaginal sonographic and pathological findings to establish diagnostic criteria. Ultrasound Obstet Gynecol 2006;28:330-4. [PubMed] [Google Scholar].

3. Vlahakis-Miliaras E, Miliaras D, Koutsoumis G, et al. Paratubal cysts in young females as an incidental finding in laparotomies performed for right lower quadrant abdominal pain. Pediatr Surg Int 1998;13:141-2. [PubMed] [Google Scholar].

4. Stenbäck F, Kauppila A. Development and classification of parovarian cysts. An ultrastructural study. Gynecol Obstet Invest 1981;12:1-0. [PubMed] [Google Scholar].

5. Betancor L, Eduvigis C, Vázquez Rueda F, et al. Quiste paratubárico en la infancia. Manejo laparoscópico. Prog Obstet Ginecol 2011;54:376-8. [Google Scholar].
6. Abad P, Obradors J, Ortuño P, et al. Torsion of paraovarian cyst in pediatrics [in Spanish]. Cir Pediatr 2005;18:46-8. [PubMed] [Google Scholar].

7. Smorgick N, Herman A, Schneider D, et al. Paraovarian cysts of neoplastic origin are underreported. JSLS 2009;13:22-6. [PMC free article] [PubMed] [Google Scholar].

8. Kajiyama A, Edo H, Takeya C, et al. Spontaneously ruptured paraovarian tumor of borderline malignancy with extremely elevated serum carbohydrate antigen 125 (CA125) levels: a comparison of the imaging and pathological features. Am J Case Rep 2017;18:919-25. [PMC free article] [PubMed] [Google Scholar].

9. Mărginean $\mathrm{CO}$, Mărginean $\mathrm{C}$, Voidăzan $\mathrm{S}$, et al. Correlations between leptin gene polymorphisms 223A/G, 1019G/A, 492G/C, 976C/A, and anthropometrical and biochemical parameters in children with obesity: a prospective case-control study in a Romanian population-The Nutrichild Study. Medicine (Baltimore) 2016;95:e3115. [PMC free article] [PubMed] [Google Scholar].

10. Kiseli M, Caglar GS, Cengiz SD et al. Clinical diagnosis and complications of paratubal cysts: review of the literature and report of uncommon presentations. Arch Gynecol Obstet 2012;285:1563-9. [PubMed] [Google Scholar].

11. Savelli L, Ghi T, De Iaco P, Ceccaroni M, Venturoli S, Cacciatore B. Paraovarian/paratubal cysts: comparison of transvaginal sonographic and pathological findings to establish diagnostic criteria. Ultrasound Obstet Gynecol. 2006;28(3):330-334. doi:10.1002/uog.2829

12. Samaha M, Woodruff JD. Paratubal cysts: frequency, histogenesis, and associated clinical features. Obstet Gynecol 1985;65:691-4. [PubMed] [Google Scholar]

13. Kazem Moslemi M, Yazdani Z. A Huge Ovarian Cyst in a Middle-Aged Iranian Female. Case Rep Oncol. 2010;3(2):165-170. Published 2010 May 7. doi:10.1159/000314525.

14. Kassidi F, Moukit M, Ait El Fadel F, El Hassani ME, Guelzim K, Babahabib A, et al. Successful Management of a Giant Ovarian Cyst: A Case Report. Austin Gynecol Case Rep. 2017; 2(1): 1012.

15. Albers C E, Ranjit E, Sapra A, et al. (January 23, 2020) Clinician Beware, Giant Ovarian Cysts are Elusive and Rare. Cureus 12(1): e6753. doi: $10.7759 /$ cureus. 6753

Citation: Hisham Hussein Imam, "A Giant Paraovarian Cyst in a single woman in her third decade: A case report, vol 3, no. 1, 2020, pp. 1-3.

Copyright (C) 2020 Hisham Hussein Imam. This is an open access article distributed under the Creative Commons Attribution License, which permits unrestricted use, distribution, and reproduction in any medium, provided the original work is properly cited. 